\title{
Awareness and Practice of Tooth Replacement among Elderly Ghanaian Adult within the Greater Accra Metropolis
}

\author{
Berko D ${ }^{1}$, Quartey-Papafio $\mathrm{N}^{2 *}$, Ampofo $\mathrm{PC}^{2,4}$, Fleischer $\mathrm{HNA}^{2}$, Tormeti $\mathrm{D}^{3}$
}

\author{
${ }^{1}$ School of Allied Health Sciences, College of Health Sciences, University of Ghana, Legon, Accra, Ghana \\ ${ }^{2}$ Biomaterials Science Department, Dental School, College of Health Sciences, University of Ghana, Legon, Accra, Ghana \\ ${ }^{3}$ Community and Preventive Dentistry, Dental School, College of Health Sciences, University of Ghana, Legon, Accra, Ghana \\ ${ }^{4}$ Restorative Dentistry Department, Dental School, College of Health Sciences, University of Ghana, Legon, Accra, Ghana
}

DOI: $\underline{10.36347 / \text { sjds.2020.v07i08.001 }}$

| Received: 04.07.2020 | Accepted: 11.07.2020 | Published: 05.08.2020

*Corresponding author: N Quartey-Papafio

\section{Abstract}

Original Research Article

Background: Tooth loss affects the oral function, physical appearance, psychological well-being and social life of a person. The use of dental prosthesis therefore becomes necessary. However, the full acceptance and use of this treatment plan has not been fully realized due to factors such as limited knowledge on oral care and tooth replacement, poverty, dental anxiety, sociodemographic location and the beliefs of people. Aim: The purpose of the study was to determine the awareness and practice of tooth replacement among older Ghanaian adults. Methods: A descriptive cross-sectional study was conducted among 100 consenting participants of age 50 years and above living in the Accra Metropolitan District in Ghana. The participants were selected using random sampling technique. The collected data were responses of structured questionnaire asking participants about the awareness and practices of tooth replacement. Data was captured using Microsoft Access and analyzed using descriptive statistics (to obtain means and frequencies) and Chi square tests from the Statistical Package for Social Science (SPSS) software version 22.The level of significance was set at 0.05 . Results: The prevalence of tooth loss and total edentulism was $66.0 \%$ and $3.0 \%$ among participants respectively. There was $90.0 \%$ awareness on tooth replacement among participants and $82.0 \%$ responded positively towards the practice of tooth replacement. This study revealed that $18.0 \%$ of subjects have utilized dental prosthesis of which $94.4 \%$ opted for removable dentures. Conclusion: Tooth loss and awareness on tooth replacement were high among majority of participants. The use of dental prostheses was low among participants. Majority of participants perceived dental prosthesis as not necessary and moreover financial constraint was a key reason for nonuse of prosthesis among participants. Increased education and improved socioeconomic status is therefore necessary to enhance the practice of tooth replacement among elderly Ghanaian adults.

Keywords: Oral Health, Tooth Loss, Edentulism, Prosthesis, Aesthetics.

Copyright @ 2020: This is an open-access article distributed under the terms of the Creative Commons Attribution license which permits unrestricted use, distribution, and reproduction in any medium for non-commercial use (NonCommercial, or CC-BY-NC) provided the original author and source are credited

\section{INTRODUCTION}

Oral health implies not only healthy teeth, but an integrated part of general health and important for the subjective well-being of people [1]. The presence of teeth plays a very significant role in an individual's capacity to bite, chew, smile, and speak. It also contributes to the overall psychological well-being of a person [2]. "Good oral health is a significant resource of social, economic and personal development of individuals" [3]. Elderly adults require more oral health care because as one ages, the integrity of the oral cavity declines. Several non-communicable diseases suffered by the elderly tend to affect the general and oral health of the person. The prescribed medications for these diseases as well as some medical conditions like diabetes, hypertension, stroke and rheumatoid arthritis usually lead to a reduced amount and quality of saliva secreted. This condition subsequently results in increased plaque formation, tooth decay, and other periodontal infections. Also as people age, certain habits like cigarette and tobacco smoking and behaviors including dietary habits practiced over a lifetime begin to show its effects ${ }^{4}$. With the advancements in dentistry and progress in oral health care in many countries, a higher number of people tend to keep more teeth into old age. However, of late, patient requirements such as aesthetics and functional comfort are considered more essential when attempting to replace missing teeth. Although several prosthodontic options for the replacement of missing teeth are available, some researchers have stressed that the acceptability of these options depends on the patient's education, economy, 
cultural background as well as the age [5]. The traditional approach resulted in a fairly consistent treatment option based on the fact that the missing teeth should always be replaced [4]. However, in less developed countries, dental care services are underutilized by many or can't be accessed at all especially in the rural areas because of the cost involved. Prosthodontic treatment cost for tooth replacement depends on the option one prefers as well as the number of teeth to be replaced [6]. It has been proven that though implant-supported prostheses can substantially improve quality of life among those who utilize them, its high cost make removable dentures the widely used treatment option to replace missing teeth [7]. Moreover, the beliefs of people have undoubtedly reduced the effectiveness of this intervention of improving oral health among the elderly. Thus, most people perceive tooth loss as a normal occurrence and tooth replacement as unnecessary [8]. The urge to go in for dental treatment depends on how knowledgeable the individual is about the situation ${ }^{6}$. High level of education, high socio-economic status and availability of dental services are also factors responsible for a positive attitude towards tooth replacement [8].

The condition of partial or complete edentulism in humans is a debilitating and irreversible condition. Tooth replacement becomes necessary as a person ages in life after several years of using the permanent dentition. This trend can be seen amongst majority in the western world and has resulted in an increasing proportion of partially dentate older patients [9]. The prevalence of tooth loss is becoming an increasingly scarce condition in high-income households in countries. Projections suggest that in future, edentulousness will be seen mainly within the older, economically deprived population [9]. More emphasis, therefore, needs to be placed on the oral health of the aging population in Ghana to avoid it. Lack of awareness on the different prosthodontic treatment options among people prevents them from availing themselves to treatment [10]. Also, though people are aware of the effects of tooth loss, "they appear to accept the limitation of a disabled mouth rather than embark on a potentially uncertain course of treatment for tooth replacement" [8].

The purpose of the study was to determine the awareness and practice of tooth replacement among elderly Ghanaian adults in the Accra Metropolitan District.

\section{MATERIALS AND METHODS}

The research was a descriptive cross-sectional study conducted among 100 consenting participants of age 50 years and above living in the Accra Metropolitan District in Ghana. The participants were selected using a simple random sampling technique.
They were requested to complete a well structured questionnaire developed and administered to the participants by trained interviewers about the awareness and practice of tooth replacement among the elderly.

The process included an interview of randomly selected individuals within localities in the Metropolis. After that, people who consented to participate were given a questionnaire each to complete.

Data obtained included their biodata, history of dental visit, knowledge about tooth replacement options, the importance of tooth replacement, history of tooth loss and reasons for non-replacement where applicable. Demographic characteristics included age, sex, ethnicity and educational attainment (school level attained). Subjects who needed assistance due to illiteracy or physical impairment were assisted to complete the questionnaire.

\section{STATISTICAL ANALYSIS}

Data was captured using Microsoft Access to organize, process and store. Means and standard deviations were calculated for all quantitative variables. Categorical variables will be summarised as proportions and percentages. Proportions and percentages will be analysed using Chi square test (at a significance level of $p<0.05)$ from the Statistical Package for Social Sciences (SPSS) version 22.

\section{RESULTS}

Table-1 Depicts information on the demographic characteristics of the respondents.

Table-1: Demographic Characteristics of the Respondents

\begin{tabular}{|c|c|c|}
\hline Demographics & Frequency $(\mathrm{N}=100)$ & Percent (\%) \\
\hline \multicolumn{3}{|l|}{ Sex } \\
\hline Male & 43 & 43.0 \\
\hline Female & 57 & 57.0 \\
\hline \multicolumn{3}{|l|}{ Age category } \\
\hline $50-59$ & 52 & 52.0 \\
\hline $60-69$ & 28 & 28.0 \\
\hline Above 70 & 20 & 20.0 \\
\hline \multicolumn{3}{|c|}{ Educational level } \\
\hline None & 10 & 10.0 \\
\hline Low & 56 & 56.0 \\
\hline High & 34 & 34.0 \\
\hline \multicolumn{3}{|l|}{ Occupation } \\
\hline Worker & 62 & 62.0 \\
\hline Retired & 26 & 26.0 \\
\hline Nonworking & 12 & 12.0 \\
\hline \multicolumn{3}{|l|}{ Ethnicity } \\
\hline Akan & 31 & 31.0 \\
\hline Ga-Adangbe & 32 & 32.0 \\
\hline Ewe & 14 & 14.0 \\
\hline Guan & 10 & 10.0 \\
\hline Northerner & 13 & 13.0 \\
\hline
\end{tabular}


The results in Table- 1 show that $57.0 \%$ of the respondents were females while the remaining $43.0 \%$ were males. In terms of the age distribution, majority $(52.0 \%)$ were between the ages of 50 and 59 years. This was followed by those between 60 and 69 years $(28.0 \%)$ and the least being those who were at least 70 years old $(20.0 \%)$. The mean age was 61.3 years. With regards to educational level, $10.0 \%$ had no formal education, $34.0 \%$ had tertiary education while the remaining had some form of education other than tertiary education. Findings also showed that $62.0 \%$ of the respondents were still working, $26.0 \%$ were retired workers while $12.0 \%$ were not working at the time of the study. Table-1, $32.0 \%$ of the respondents were GaAdangbe, $31.0 \%$ Akans, $14.0 \%$ Ewes, $13.0 \%$ Northerners, and $10.0 \%$ were Guans. The findings on the demographic characteristics of the respondents are somewhat representative of the study population.

The frequency of annual dental visits and the prevalence of tooth loss is presented in Table- 2 .

Table-2: Dental Visits and Prevalence of Tooth Loss

\begin{tabular}{|l|l|l|}
\hline Demographics & Frequency (N=100) & Percent (\%) \\
\hline Frequency of Yearly Dental Visit & & \\
\hline Less than two visits & 14 & 14.0 \\
\hline More than two visits & 7 & 7.0 \\
\hline Hardly & 41 & 41.0 \\
\hline Never & 38 & 38.0 \\
\hline Purpose of Yearly Dental Visit & & \\
\hline Tooth extraction & 45 & 72.6 \\
\hline Scaling and polishing & 15 & 24.2 \\
\hline Periodontal therapy & 18 & 29.0 \\
\hline Prosthodontic treatment & 6 & 9.1 \\
\hline Root canal therapy & 5 & 7.6 \\
\hline Others & 5 & 7.6 \\
\hline Ever lost a tooth & & \\
\hline Yes & 66 & 66.0 \\
\hline No & 34 & 34.0 \\
\hline Number of tooth loss & & \\
\hline One & 21 & 31.8 \\
\hline Two & 17 & 25.8 \\
\hline Three & 2 & 3.0 \\
\hline Four & 8 & 12.1 \\
\hline Five & 4 & 6.1 \\
\hline More than five & 12 & 18.2 \\
\hline All teeth & 2 & 3.0 \\
\hline Frequency of seeing people with missing teeth & & \\
\hline Scarcely & 14 & 14.0 \\
\hline Less often & 35 & 35.0 \\
\hline More often & 44 & 74.0 \\
\hline Never & 7 & \\
\hline & & \\
\hline
\end{tabular}

Results show that out of the 62 respondents who indicated that they had visited the dental clinic in the past year, $14.0 \%$ had visited the clinic not more than twice, and $41.0 \%$ hardly visited the clinic while only $7.0 \%$ had visited the clinic more than twice. The reasons for visiting the clinic were for tooth extraction (72.6\%), periodontal therapy $(29.0 \%)$, scaling and polishing $(24.2 \%)$, prosthodontic treatment $(9.1 \%)$, root canal therapy $(7.6 \%)$ and other unspecified reasons accounted for $7.6 \%$.

On the prevalence of tooth loss, about two thirds $(66.0 \%)$ of the respondents indicated that they had ever lost a tooth. Out of the 66 respondents who had lost one tooth or more, the majority $(31.8 \%)$ of them had lost a tooth. This was followed by those who lost two teeth $(25.8 \%)$, more than five teeth $(18.2 \%)$, four teeth $(12.1 \%)$, five teeth $(6.1 \%)$, three teeth $(3.0 \%)$ and all teeth $(3.0 \%)$. Also, the study found that $93.0 \%$ had never seen an older adult with a missing tooth.

A cross-tabulation using Pearson's Chi-square and correlation to determine the strength of association between demographic characteristics and prevalence of tooth loss is illustrated in Table-3. 
Table-3: Association between Demographics and Prevalence of Tooth Loss

\begin{tabular}{|c|c|c|c|}
\hline \multirow[t]{2}{*}{ Demographics } & \multicolumn{2}{|c|}{ Ever lost a tooth } & \multirow[t]{2}{*}{ P-value } \\
\hline & Yes $(\mathrm{N}=66)$ & No $(N=34)$ & \\
\hline \multicolumn{4}{|l|}{ Sex } \\
\hline Male & $27(62.8 \%)$ & $16(37.2 \%)$ & \multirow[t]{2}{*}{0.670} \\
\hline Female & $39(68.4 \%)$ & $18(31.6 \%)$ & \\
\hline \multicolumn{4}{|l|}{ Age category } \\
\hline $50-59$ & $26(50.0 \%)$ & $26(50.0 \%)$ & \multirow[t]{3}{*}{0.000} \\
\hline $60-69$ & $20(71.4 \%)$ & $8(28.6 \%)$ & \\
\hline Above 70 & $20(100.0 \%)$ & $0(0.0 \%)$ & \\
\hline \multicolumn{4}{|c|}{ Educational status } \\
\hline None & $53(80.3 \%)$ & $13(19.7 \%)$ & \multirow[t]{3}{*}{0.270} \\
\hline Low & $4(44.4 \%)$ & $5(55.6 \%)$ & \\
\hline High & $14(70.0 \%)$ & $6(30.0 \%)$ & \\
\hline \multicolumn{4}{|l|}{ Occupation } \\
\hline Working & $34(54.8 \%)$ & $28(45.2 \%)$ & \multirow[t]{3}{*}{0.011} \\
\hline Retired & $22(84.6 \%)$ & $4(15.4 \%)$ & \\
\hline Not working & $10(83.3 \%)$ & $2(16.7 \%)$ & \\
\hline \multicolumn{4}{|l|}{ Ethnicity } \\
\hline Akan & $15(48.4 \%)$ & $16(51.4 \%)$ & \multirow[t]{5}{*}{0.101} \\
\hline Ga-Adangbe & $26(81.2 \%)$ & $6(18.8 \%)$ & \\
\hline Ewe & $9(64.3 \%)$ & $5(35.7 \%)$ & \\
\hline Guan & $7(70.0 \%)$ & $3(30.0 \%)$ & \\
\hline Northerner & $9(69.2 \%)$ & $4(30.8 \%)$ & \\
\hline
\end{tabular}

Results showed that age category $(\mathrm{p}=0.000)$, and occupation status $(\mathrm{p}=0.011)$ indicated significant association with the prevalence of tooth loss. In terms of age distribution, the study found that the prevalence of tooth loss increased with advancing age. Thus, while half of the respondents between 50 and 59 years lost their teeth, $(71.4 \%)$ of the respondents between 60 and 69 years lost their teeth and all the respondents who were at least 70 years had lost one tooth or more.
In Table-3, it was found that $\operatorname{sex}(\mathrm{p}=0.670)$, educational status $(\mathrm{p}=0.270)$ and ethnicity $(\mathrm{p}=0.101)$ of the respondents were not significantly associated with the prevalence of tooth loss. Therefore, the differences could be due to chance.

The association between dental visits and the prevalence of tooth loss is depicted in Table 4.

Table-4: Association between Dental Visits and Prevalence of Tooth Loss
\begin{tabular}{|l|l|l|l|}
\hline Selected variables & \multicolumn{2}{|l|}{ Ever lost a tooth } & \multirow{2}{*}{ P-value } \\
\cline { 2 - 3 } & Yes (N=66) & No (N=34) & \\
\hline Frequency of Yearly Dental Visit & & \\
\hline Less than two visits & $8(57.1 \%)$ & $6(42.9 \%)$ & \multirow{2}{*}{0.001} \\
\hline More than two visits & $7(100.0 \%)$ & $0(0.0 \%)$ & \\
\hline Hardly & $34(82.9 \%)$ & $7(17.1 \%)$ & \\
\hline Never & $17(44.7 \%)$ & $21(55.3 \%)$ & \\
\hline Purpose of yearly visit & & & \\
\hline Tooth extraction & $44(97.8 \%)$ & $1(2.2 \%)$ & 0.000 \\
\hline Scaling and polishing & $9(60.0 \%)$ & $6(40.0 \%)$ & 0.768 \\
\hline Periodontal therapy & $14(77.8 \%)$ & $4(22.2 \%)$ & 0.285 \\
\hline Prosthodontic treatment & $6(100.0 \%)$ & $0(0.0 \%)$ & 0.093 \\
\hline Root canal therapy & $5(100.0 \%)$ & $0(0.0 \%)$ & 0.163 \\
\hline Others & $2(40.0 \%)$ & $3(60.0 \%)$ & 0.125 \\
\hline
\end{tabular}

Results in Table-4 shows that the frequency of yearly dental visits and prevalence of tooth loss is significantly associated $(\mathrm{p}=0.001)$. In addition the results indicated that the respondents who visited the dental clinic for at least twice had lost at least a tooth. Also, $55.3 \%$ of the respondents who had never visited a 
dental clinic had lost no tooth. $97.8 \%$ of the respondents who lost a tooth went to the dental clinic for a tooth extraction. There was significant association $(p=0.000)$ between respondents who visit the clinic yearly for tooth extraction and prevalence of tooth loss. With the exception of tooth extraction $(p=0.000)$ there was no significant association between the other purposes of yearly dental visits $(\mathrm{p}>0.05)$ and prevalence of tooth loss.

The knowledge of the respondents on tooth replacement and its importance is depicted in Table-5.

Table-5: Knowledge on Tooth Replacement and its Importance

\begin{tabular}{|l|l|l|}
\hline Knowledge on tooth replacement & Frequency (N=100) & Percent (\%) \\
\hline Ever heard of tooth replacement & & \\
\hline Yes & 90 & 90.0 \\
\hline No & 10 & 10.0 \\
\hline Tooth replacement options & & \\
\hline Removable denture & 68 & 75.6 \\
\hline Fixed denture & 21 & 23.3 \\
\hline Implant prosthesis & 1 & 1.1 \\
\hline Tooth replacement is important & & \\
\hline Yes & 82 & 91.1 \\
\hline No & 8 & 8.9 \\
\hline Importance of tooth replacement & & \\
\hline Good appearance and function & 72 & 87.8 \\
\hline No response & 10 & 12.2 \\
\hline Tooth replacement is not important & & 12.5 \\
\hline Causes problems & 1 & 12.5 \\
\hline It is risky & 1 & 75.0 \\
\hline Not necessary & 6 & \\
\hline
\end{tabular}

The result shows that $90.0 \%$ have heard of tooth replacement. Out of the $90.0 \%$ respondents who had heard of tooth replacement, $75.6 \%$ knew of removable dentures, $23.3 \%$ knew of fixed partial denture, and only (1.1\%) knew of implant prosthesis. On the importance of tooth replacement, $91.1 \%$ of the respondents affirmed that tooth replacement is important, $87.8 \%$ mentioned that tooth replacement gives a good appearance, improves oral function and enhances social well-being. $75 \%$ of the respondents who indicated that tooth replacement was not important mentioned that tooth replacement is not necessary.

Table-6: Prevalence of Denture use and Associated Factors

\begin{tabular}{|l|l|l|}
\hline Prevalence of denture use & Frequency (N=100) & Percent (\%) \\
\hline Ever gone for tooth replacement & & \\
\hline Yes & 18 & 18.0 \\
\hline No & 82 & 82.0 \\
\hline The purpose of tooth replacement & & \\
\hline Aesthetics & 12 & 66.7 \\
\hline Function & 14 & 77.8 \\
\hline For both aesthetics and function & 8 & 44.4 \\
\hline Type of tooth replacement option & & \\
\hline Removable denture & 17 & 94.4 \\
\hline Fixed denture & 2 & 11.1 \\
\hline Reasons for choice of type of replacement & & \\
\hline Cost & 11 & 61.1 \\
\hline Comfortability & 7 & 38.9 \\
\hline Durability & 8 & 44.4 \\
\hline Reasons for non-use of tooth replacement & & \\
\hline Financial constraints & 21 & 25.6 \\
\hline Dental fear and anxiety & 4 & 4.9 \\
\hline Non-availability of dental services & 2 & 2.4 \\
\hline Not necessary & 28 & 34.1 \\
\hline Distance & 5 & 6.1 \\
\hline Ignorance & 3 & 3.7 \\
\hline & & \\
\hline
\end{tabular}


Results, as shown in Table-6, reveal that only $18.0 \%$ of the respondents had gone for tooth replacement. However, majority $(82.0 \%)$ of the respondents had never gone for tooth replacement. On the reasons for the use of tooth replacement options, $(77.8 \%),(66.7 \%)$, and $(44.4 \%)$ respondents went for a tooth replacement options for function, aesthetic as well for both purposes respectively.

On the type of tooth replacement option, $94.4 \%$ of the respondents went for removable dentures and $11.1 \%$ went for fixed partial dentures. The responses exceeded $100.0 \%$ because some respondents went for both tooth replacement options. On the reasons for the choice of a particular type of tooth replacement option, $61.1 \%$ went for cost, $44.4 \%$ went for durability and $38.9 \%$ went for comfortability. On the reasons respondents did not use dentures, $34.1 \%$ said they were not necessary, $25.6 \%$ were due to financial constraints, $6.1 \%$ were due to the distance to dental facilities, $4.9 \%$ was due to dental fear and anxiety, $3.7 \%$ was due to ignorance and $2.4 \%$ due to the non-availability of dental services.

\section{DISCUSSION}

Tooth loss indicates a major public health concern in many countries across the world, in addition it affects dietary habits, appearance and communication [11]. The discovery and use of several restorative options to replace missing teeth have contributed immensely towards the well-being of people most especially the elderly [8].

This study was conducted to determine among elderly Ghanaian adults in the Accra Metropolitan district, the prevalence of tooth loss, awareness and practice of tooth replacement and reasons why people do not go in for prosthodontic treatment when required.

The results of the study indicated (Table-2) that tooth loss was a common occurrence among the Ghanaian elderly. Majority of the respondents (97\%) had lost some of their teeth and 3.0\% had lost all their teeth. The result agrees with other studies carried out in the Moradabad district in India [8, 12] and Ghana [13]. In addition another study by WHO [14] in 2017 also agrees with the findings of this study. However similar studies carried out in China, South Africa and India had contradictory results [14]. The percentage of edentulous people in this study were similar to other studies in Shandong province, China [15] and Southern Vietnam [16].

Kailembo et al., [14] reported a significant association between old age and edentulism when younger and older aged groups were compared.

Regarding the association between gender, educational status and tooth loss (Table-3), results in this study indicated that there was no signficant association between gender and tooth loss even though tooth loss was higher in females than males. In addition there was also no significant associaation between educational status and tooth loss. However respondnets with no education had higher tooth loss than those with higher level of education. This compares favouably with Hewlett et al., [13] and Esan et al., [17]. The findings of this study is in contrast with the results of Raj et al., [12] which showed that out of $84.3 \%$ of participants with missing teeth, males showed a higher frequency of missing teeth than females.

In terms of dental visit and prevalence of tooth loss, the study as indicated in Table 4 shows that majority of the respondents $(97.8 \%)$ who visited the dental clinic went for tooth extraction. This may have accounted for the significant association between the prevalence of tooth loss and the yearly dental visits of the respondents. This result agrees with the findings of the study by Yadav et al., [8] and Wandera et al., [18].

Majority of the respondents (90\%) as indicated in Table-5 had knowledge about tooth replacement treatment options. With regards to tooth replacement options, (75.6\%) respondents expressed knowledge on removable dentures followed by fixed dentures $(23.3 \%)$ and dental implants was $(1.1 \%)$. This finding is in agreement with the study by Jayasinghe et al., [5], and Raj et al., [12]. However these results disagreed with the study by Yadav et al., [8] which evidenced a considerable number of people were aware of fixed and implant prostheses.

Regarding the importance of tooth replacement $(91.1 \%)$ of respondents in this study affirmed the practice of going in for missing teeth replacement as important and good. However only (8.9\%) indicated that tooth replacement was not necessary stating reasons that it was normal for teeth to be lost with increasing age. This is consistent with the studies by Jayasinghe et al., [5] and Reddy et al., in 2016 [19].

In terms of the use of dental prosthesis in this study (Table-6), only $18 \%$ of respondents with missing teeth had gone in for their teeth to be replaced. This result disagrees with the study by Yadav et al., [8] which reported a greater proportion $(57.1 \%)$ had either replaced their teeth or showed the desire of getting it replaced. Most respondents who didn't go in for dental prosthesis nor had a desire of getting their missing teeth replaced, indicated that the cost of dentures were expensive.

However $4.9 \%$ of respondents stated that dental fear and anxiety, $3.7 \%$ stated ignorance, $6.1 \%$ stated distance to dental care facilities, and $2.4 \%$ stated non-availability of dental facilities prevented them from utilizing dental prosthesis. $34.1 \%$ of respondents stated that tooth replacement (dentures) were necessary. These 
results correspond to the findings by Yadav et al., [8], Raj et al., [12] and Esan et al., [17]. However, Mukatash et al., [20], Jayasinghe et al., [5], and AlQuran et al., [21] reported that fixed prostheses were more preferred and utilized than removable dentures.

Concerning the types of prosthesis utilized by participants, this study indicated that a higher percentage of respondents $(94.4 \%)$ of those who desired prostheses used removable dentures than fixed prostheses $(11.1 \%)$. No participant utilized an implant prosthesis.

As indicated in Table- 6 respondents who used dental prostheses sited aesthetics $66.7 \%$ and function $77.8 \%$ as the purpose for tooth replacement and $44.4 \%$ of respondents preferred a combination of aesthetics and function. This agrees with the study by Jayasinghe et al. ${ }^{5}$ and Suresh and Sharma [22]. In a similar study, Mukatash et al., reported that aesthetics was more important than function for the majority of individuals who went in for tooth replacement ${ }^{20}$, this disagreed with the findings of this study.

$61.1 \%$ respondents in this study (Table-6) indicated cost, (44.4\%) durability and (38.9\%) comfortability as factors that influenced their choice of prosthetic type. This is consistent with the report by AlQuran et al., [21] which reported that financial status and comfort influenced a patient's choice of prosthetic treatment. Mukatash et al., [20] also reported similarly that, economic status was an important factor that affected the choice of tooth replacement options by patients.

\section{CONCLUSION}

The majority of adults in this study had missing teeth which occurred with increasing age. Most subjects were aware of the practice of tooth replacement and majority expressed greater awareness on removable dentures compared to fixed and implant prosthesis. A lower proportion of participants with missing teeth had replaced them with removable dentures. Adults in this study used dentures mainly to improve their masticatory functions as well as speech, while others utilized dentures to enhance their appearance. It was noted that financial constraints prevented a significant number of adults from seeking prosthetic treatment. Tooth loss was perceived by most subjects as normal and as a result tooth replacement was not necessary.

\section{REFERENCES}

1. Madléna $M$, Hermann $P$, Jáhn $M$, Fejérdy $P$. Caries prevalence and tooth loss in Hungarian adult population: Results of a national survey. BMC Public Health. 2008; 8: 1-7.

2. Tsai SJ, Lin MS, Chiu WN, Jane SW, Tu LT, Chen, MY. Factors associated with having less than 20 natural teeth in rural adults: a cross- sectional study. BMC oral health. 2015; 15: 158165.

3. Khan SA, Dawani N, Bilal S. Perceptions and myths regarding oral health care amongst strata of low socio economic community in Karachi, Pakistan. J Pak Med Assoc. 2012; 62: 1198-203.

4. Wennström A, Ahlqwist M, Stenman U, Björkelund C, Hackberry M. Trends in tooth loss in relation to socio-economic status among Swedish women, aged 38 and 50 years: repeated cross-sectional surveys 1968-2004. BMC Oral Health. 2013; 13: 63-70.

5. Jayasinghe RM, Perera J, Jayasinghe V, Thilakumara IP, Rasnayaka S, Shiraz MHM, Kularatna S. Awareness, attitudes, need and demand on replacement of missing teeth among a group of partially dentate patients attending a University Dental Hospital. BMC Research Notes. 2017; 10: 334-340.

6. Newman MG, Takei H, Klokkevold PR., Carranza FA. Carranza's clinical periodontology. St. Louis, Missouri. 2011 Elsevier Health Sciences.

7. Yen YY, Lee HE, Wu YM, Lan SJ, Wang WC, Du JK, Hsu KJ. Impact of removable dentures on oral health-related quality of life among elderly adults in Taiwan. BMC Oral Health. 2015; 15: 1-12.

8. Yadav V, Tandon V, Pal S, Ravishankar TL, Kaur H, Moudgil M. Oral Health Knowledge, Attitude and Practices among Adults toward Tooth Loss and Utilization of Dental Services in Moradabad District. J. of Orofacial Res. 2012; 2: 192-197.

9. Wallace S, Samietz S, Abbas M, McKenna G, Woodside JV, Schimmel M. Impact of prosthodontic rehabilitation on the masticatory performance of partially dentate older patients: Can it predict nutritional state? Results from a RCT. J. of Dent. 2018; 68: 66-71.

10. Menezes M, Aras M. Prosthodontic Awareness and Fulfillment of Prosthodontic Need in Rural Areas of Goa. J. Indian Dent. Ass. 2009;11:368.

11. Petersen PE, Yamamoto T. Improving the oral health of older people: the approach of the WHO Global Oral Health Programme. Community dentistry and oral epidemiology. 2005; 33: 81-92.

12. Raj N, Reddy N, Japatti S, Thomas M, Uthappa R. Knowledge, attitudes towards prosthodontics rehabilitation and utilization of dental services among Songadh and Amargadh Population. J Dent Med Sci. 2014; 3: 1-6.

13. Hewlett SA, Yawson AE, Calys-Tagoe BNL, Naidoo N, Martey P, Chatterji S, Biritwum RB. Edentulism and quality of life among older Ghanaian adults. BMC Oral Health. 2015; 15: 1-9.

14. Kailembo A, Preet R, Williams JS. Common risk factors and edentulism in adults, aged 50 years and over, in China, Ghana, India, and South Africa: results from the WHO Study on global Ageing and adult health (SAGE). BMC oral health. 2017; 17: $1-16$. 
15. Zhang Q, Witter DJ, Bronkhorst EM, Creugers NH. Dental and prosthodontic status of an over 40year-old population in Shandong Province, China. BMC Public Health. 2011; 11: 420-430.

16. Nguyen TC, Witter DJ, Bronkhorst EM, Truong NB, Creugers NH. Oral health status of adults in Southern Vietnam-a cross-sectional epidemiological study. BMC Oral Health. 2010; 10: 2-12.

17. Esan TA, Olusile AO, Akeredolu PA, Esan AO. Socio-demographic factors and edentulism: The Nigerian experience. BMC Oral Health. 2004; 4: 3-8.

18. Wandera MN, Engebretsen IM, Rwenyonyi CM, Tumwine J, Åstrøm AN, Promise EBF study group. Periodontal status, tooth loss and selfreported periodontal problems effects on oral impacts on daily performances, OIDP, in pregnant women in Uganda: a cross-sectional study. Health and quality of life outcomes. 2009; 7: 89-98.
19. Reddy NR, Ibrahim EE, Vempalli S, Al Sanabani F. Perception and Awareness of Prosthodontic Rehabilitation among Jazan Population in the Southern Region of Saudi Arabia. Global Journal of Medical Research: J Dent. \& Otolaryngology. 2016; 16:1-8

20. Mukatash GN, Al-Rousan M, Al-Sakarna B. Needs and demands of prosthetic treatment among two groups of individuals. Ind. J. of Dent. Res. 2010; 21: 564-567.

21. Al-Quran FA, Al-Ghalayini R F, Al-Zu'bi BN. Single-tooth replacement: factors affecting different prosthetic treatment modalities. BMC oral health, 2011; 11:34-40.

22. Suresh S, Sharma S. A clinical survey to determine the awareness and preference of needs of a complete denture among complete edentulous patients. J. of Int. Oral Health. 2010; 2:65-70. 